\title{
Trait Impulsivity/Attention-Deficit/Hyperactivity Disorder A Genetic Liability for Criminality
}

Robert Eme*

Illinois School of Professional Psychology at Argosy University, Schaumburg Campus

Received: September 30, 2016; Accepted: December 16, 2016; Published: December 28, 2016

*Corresponding author: Getinet Ayano, chief psychiatry professional and mhGap coordinator at Research and Training Department, Amanuel Mental Specialized Hospital, Addis Ababa, PO box: 1971 Ethiopia, Tel:+251927172968; E-mail: ayanogetinet@yahoo.com

\begin{abstract}
Two recent comprehensive reviews and meta-analyses concluded that Attention-deficit/hyperactivity Disorder is a substantial longterm risk factor for criminality. The meta-analyses offered a number of possible explanations for this finding, including that of a shared genetic liability. This paper reviewed the research that provided robust support for this possibility as presented in one of the major models in developmental psychopathology for the development of antisocial behavior.
\end{abstract}

Keywords: Attention-deficit/hyperactivity Disorder; Criminality;

\section{Introduction}

Attention-Deficit/Hyperactivity Disorder (ADHD) is the diagnosis given to juveniles and adults who present with impairing symptoms of attention and/or impulsivity and hyperactivity [1]. Its importance is underscored by the fact that it is one of the most prevalent juvenile disorders as well as one of the most common reasons children with behavioral problems are referred to medical and mental health practitioners in the United States [2]. In addition, it substantially increases the risk for a kaleidoscope of long-term adverse outcomes [3]. Among the multiple adverse outcomes, two recent comprehensive reviews and meta-analyses $[4,5]$ provided resounding confirmation of the conclusion of a prior qualitative review [6] that childhood ADHD poses a substantial long-risk criminality In brief, the two metaanalyses found that compared to non-affected controls, males with childhood ADHD are at a 2-3-fold increased risk of being arrested, convicted, or incarcerated in adulthood. In addition, the reviews found that risk for criminality increased with severity of childhood ADHD and that childhood ADHD predicted an earlier onset of antisocial behavior and increased risk of recidivism. The meta-analyses offered a number of possible explanations for this substantial long-term risk for criminality, including that of a shared genetic liability. The purpose of this paper is to discuss this possibility in depth in terms of one of the major models in developmental psychopathology for the development of antisocial behavior.

This genetic liability is conceptualized as a necessary but insufficient etiological agent for progression to more serious antisocial behaviors across development which requires complex longitudinal transactions between this liability and various environmental risk factors (e.g., maltreatment, coercive parenting, deviant peer affiliation, neighborhood criminality). More specifically, the model proposes that beginning with in early childhood the behavioral and emotional impulsivity of ADHD, in an interaction with environmental risk factors, can progress to the development of increasingly more severe disorders of Oppositional Defiant Disorder (ODD), child-onset Conduct Disorder (CD), Substance Use Disorders (SUD), and juvenile delinquency and adult criminality. A developmental pathway refers to a sequence and timing of behavioral continuities and transformations across development with individuals differing in their propensity to progress along the successive behavior represented by the pathway. Progress along the pathway is probabilistic, not deterministic $[11,12]$. This paper will present a version of this pathway model as well as discuss some of the most important environmental risk factors that promote progression along the pathway.

Lastly, it should be noted that this model does not purport to be the only pathway to criminality, but only a common occurring, important pathway that provides a convincing explanation for the theory of a shared genetic liability between ADHD and criminality. There are obviously other pathways such as adolescent-onset antisocial behavior which current research has now shown is not always time-limited somewhat normative behavior, but in many instances can progress to adult criminality [13].

\section{Attention-Deficit/ Hyperactivity Disorder}

Several lines of research converge to provide convincing evidence that trait impulsivity expressed in preschool ADHD is a genetic liability that serves as a first stage in an antisocial pathway that can culminate in juvenile delinquency and adult criminality. First, by way of prologue, factor analyses of the externalizing spectrum disorders have yielded a single higher-order factor that account for much of the covariation among first order factors such as ADHD, ODD, CD and subsequent juvenile delinquency and adult criminality $[7,8,9,10]$. Second, extensive research strongly indicates that this single higher order factor is trait impulsivity 
(behavioral and emotional) and that this factor is virtually equivalent to ADHD. This evidence comes from three different sets of findings. First, multiple studies have found that "males who develop Antisocial Personality Disorder (ASPD) usually traverse a developmental trajectory that begins in preschool with ADHD, followed by ODD, childhood-onset CD, SUDs, and incarceration and recidivism. This developmental pathway may account for most individuals who engage in lifelong delinquent behavior" [9]. Second, this finding receives impressive support from the research that strongly links impairments in self-control --which can be broadly defined as the ability to flexibly control/ regulate attention, behavior, and emotion in the service of valued goals and standards -- to juvenile and adult criminal behavior $[15,16]$. Indeed, self-control may be the single most important variable in explaining developmental origins of antisocial behavior $[17,18]$. Third, since the core features of ADHD include behavioral and emotional impulsivity $[19,20]$, ADHD is widely conceptualized as a disorder of self-regulation [21, 22]. Indeed, Nigg [22] has declared ADHD to be "paradigmatic of problems in the domain of self-regulation." Thus, a very strong argument can be made that trait impulsivity expressed early in life as ADHD is potent liability for the development of antisocial behavior. Lastly, there is overwhelming, voluminous evidence that this liability of ADHD has very strong genetic influences, as the core symptoms are approximately $75 \%$ heritable [23].

In sum, the model of preschool ADHD as a genetic liability in the first stage of important antisocial pathway that can culminate in adult criminality is firmly established.

\section{Oppositional Defiant Disorder}

The second stage in the antisocial pathway is Oppositional Defiant Disorder (ODD) defined as a recurrent and pattern of angry, irritable, argumentative, defiant, or vindictive behavior [1]. ODD, which occurs on average in $65 \%$ of juveniles with ADHD and in as many as $84 \%$ of clinic-referred cases, is the most common comorbid condition of ADHD in juveniles [19, 24]. This progression from ADHD to ODD is best explained by the ADHD symptoms of behavioral and emotional impulsivity which greatly increase the risk for coercive, oppositional interchanges with significant others in the child's life [9, 19, 25]. Indeed, it is estimated that a typical child with ADHD has an astonishing half a million of these negative interchanges each year [26]. For example, a recent longitudinal study of preschool children with ADHD found increases in argumentative/defiant ODD symptoms over a three-year period [27].This coercive dynamic whereby individuals use aversive behaviors to attain access to rewarding resources and to reduce unpleasant experiences is a major etiological mechanism in the development of more severe antisocial behavior such as conduct disorder [28]. This dynamic is most likely to occur when children exhibit what has been termed the headstrong (e.g., defiant, disobedient) characteristics of ODD rather than the irritability characteristics (e.g., angry outbursts and tantrums $[29,30]$.

\section{Conduct Disorder}

Conduct Disorder (CD) is defined as a recurrent pattern of behavior that violates the rights of others or in which major age- appropriate societal norms or rules are violated [1]. Although highly correlated, ODD and CD are different enough to warrant consideration as different dimensions of deviant behavior [31]. In this progression in the worsening antisocial pathway, ODD's role as a developmental precursor to $\mathrm{CD}$ is well documented [32]. It is now understood that far from being a benign, milder form of $\mathrm{CD}$, ODD plays a key role in the development of CD and is one of the strongest predictors of the onset of $\mathrm{CD}$ and of the course of $\mathrm{CD}$ symptoms over time [33]. In addition, although the majority of children with ODD do not go on to develop CD [33], if childhoodonset $\mathrm{CD}$ develops, it is almost always preceded developmentally by ODD [34]. The progression from ODD to CD is most likely to occur when environmental risk factors such as maltreatment, neglect, hostile parenting, neighborhood violence and other forms of adversity increases rather than decreases the deviance proneness of ADHD/ODD [9, 32, 35].

\section{SUD}

Substance use, which includes smoking, drinking alcohol or using other addictive substances, exists on a continuum ranging from no use on one end; to use that does not involve negative consequences, to risky use, to a substance use disorder (SUD) [36]. SUD is characterized by inability to consistently abstain, impairment of behavioral control, craving, and significant problems in behavior and interpersonal relationships [36]. SUD is among the most prevalent mental health conditions in the United States [37] as well as a worldwide major public health problem [38]. Of the multiple pathways that can lead to SUD, what is termed the deviance proneness pathway in the SUD literature is the most important $[39,40]$. This model, which is rooted in the high co-occurrence between antisocial behavior and substance abuse, proposes that SUD reflects a generalized tendency towards deviance proneness For example, there is virtually unanimous agreement that, "the best-known correlate of ADHD that is omnipresent in discussions of SUD risk for ADHD is CD" [40]. Impressive support for this model was recently provided in a recent study [41] that modeled growth in ADHD and CD from age 5 to age 18 in a clinical ADHD sample and a comparison group as they related to substance use outcomes in adolescence. Results indicated that when compared to controls, adolescents diagnosed with ADHD in early childhood (ages 4-7) were not only more likely to try cigarettes, initiate alcohol use at early ages, and smoke marijuana more frequently, but they were also 4 to 5 times more likely to escalate to heavy cigarette and marijuana use after trying these substances once. Further, and more importantly, their model found that growth in ADHD symptoms over childhood was the strongest predictor of growth in $\mathrm{CD}$ symptoms that in turn was the strongest predictor of substance use in adolescence. Hence, the study concluded that the reasons adolescents with ADHD engage in more prevalent substance use than controls "may be largely [italics added], but not entirely, attributable to very early ADHD symptoms" [41].

Progression from CD to SUD is most likely to occur through the mechanism of deviant peer association specifically, peer relationships are a domain of great difficulty for children with 
ADHD such that between 50 and $80 \%$ of children with ADHD will experience peer rejection [42]. This exclusion from the conventional peer group, combined with academic failure which is very common for those with ADHD/CD [43] increases the likelihood that they will elect to associate with similarly excluded peers, who in turn are more likely to engage in deviant behaviors such as risky substance use $[39,40]$

\section{Criminality}

Numerous longitudinal studies have consistently found that CD and SUD increases risk for delinquent behavior $[4,44]$. Namely, youth with CD "as adolescents...may then become further attached to a life of crime by developing substance use problems" [44] Hence, it comes as no surprise that this attachment to a life of crime greatly increases the risk for progression to adult criminality, such that most adult offenders will have been adolescent offenders [45].

\section{Conclusion}

Findings presented above provided strong support for a developmental pathway of various antisocial behaviors culminating in criminal behavior that is initiated by the genetic liability of trait impulsivity, expressed early in life as the hyperactive/impulsive and combined presentations of ADHD. The progression along a pathway of increasingly more severe antisocial behaviors is propelled by interplay between this genetic liability and various adverse environmental risk factors. This developmental pathway characterizes many, though certainly not all, individuals who engage in criminal behavior. In sum then, among the possible explanations for the substantial long-term risk for criminality posed by ADHD, there is robust support for that of a shared genetic liability.

\section{References}

1. American Psychiatric Association. Diagnostic and statistical manual of mental disorders 5th ed. Washington, DC. 2013.

2. Barkley R. Attention-deficit hyperactivity disorder: A handbook for diagnosis \& treatment 3rd Ed. New York: Guilford Press. 2015.

3. Owens E, Cardoos S, Hinshaw S. Developmental progression and gender differences among individuals with ADHD. In R. Barkley Ed. Attention-deficit hyperactivity disorder 4th Ed. New York: Guilford. 2015;223-255.

4. Mohr-Jensen C, Steinhausen H. A meta-analysis and systematic review of the risks associated with childhood attention-deficit/ hyperactivity disorder on long term outcome of arrests, convictions, and incarcerations. Clinical Psychology Review. 2016;48:32-42. Doi:10.1016/j.cpr.2016.05.002.

5. Erskine H, Norman R, Ferrari A, Chan G, Copeland W, Whiteford H, et al. Long-term outcomes of Attention-Deficit/Hyperactivity Disorder and Conduct Disorder: A systematic review and meta-analysis. Journal of the American Academy of Child and Adolescent Psychiatry. 2016;55:841-850. Doi:10.1016/j.jaac.2016.06.016.

6. Eme R. ADHD and the Biological Roots of Violence. The ADHD Report. 2014;23(7). doi:10.1521/adhd.2014.22.7.1.

7. Beauchaine T, Hinshaw S, Pang K. Comorbidity of Attention-Deficit/ Hyperactivity Disorder and early-onset conduct disorder: Biological, environmental, and developmental mechanisms. Clinical Psychology: Science and Practice. 2010;17:327-336.

8. Beauchaine T, McNulty T. Comorbidities and continuities as ontogenic processes: towards a developmental spectrum model of externalizing psychopathology. Development and Psychopathology. 2013;25(4 pt 2):1505-1528. doi:10.1017/S0954579413000746.

9. Beauchaine T, Shader C, Hinshaw S. An ontogenic processes model of externalizing psychopathology. In $\mathrm{T}$ Beauchaine, $\mathrm{S}$ Hinshaw Eds. The Oxford handbook of externalizing spectrum disorders. New York: Oxford University Press. 2015;485-502. DOI:10.1093/ oxfordhb/9780199324675.013.15.

10. Beauchaine T,Zisner A,ShaderC. Traitimpulsivity and the externalizing spectrum. Annual review of clinical psychology. Washington DC. 2017;DOI:10.1146/annurev-clinpsy-021815-093253.

11. Loeber R, Burke J. Developmental pathways in juvenile externalizing and internalizing Problems. Journal of Research on Adolescence. 2011;21:34-46. DOI: 10.1111/j.1532-7795.2010.00713.x

12. Hayden E, Mash E. Child psychopathology: A developmental-systems perspective. In EJ Mash, RA Barkley Eds. Child psychopathology 2nd ed. New York: Guilford Press. 2014;3-71.

13. Fairchild G, van Goozen S, Calder A, Goodyer I. Research Review: Evaluating and reformulating the developmental taxonomic theory of antisocial behaviour. Journal of Child Psychology and Psychiatry. 2013;54(9):924-940. doi:10.1111/jcpp.12102.

14. Achenbach T. Internalizing/Externalizing problems: Review and recommendations for clinical and research applications. Journal of the American Academy of Child and Adolescent Psychiatry. 2016;55(8):645-657. DOI:10.1016/j.jaac.2016.05.012.

15. Stifter C, Dollar J. Temperament and developmental psychopathology. In D. Cicchetti Ed. Developmental psychopathology 3rd ed. New York: Wiley. 2016;4:546-607. DOI:10.1002/9781119125556.devpsy411.

16. DeLisi M, Vaughn M. Foundation for a temperament-based theory of antisocial behavior and criminal justice system involvement. Journal of Criminal Justice. 2014;42(1):10-25. Doi:10.1016/j. jcrimjus.2013.11.001.

17. Moffitt T. Self-control, then and now. In R Loeber, B Welsch Eds. The future of criminology. New York: Oxford University Press. 2012;4045. DOI:10.1093/acprof:oso/9780199917938.003.0005

18. Moffitt T, Arseneault L, Belsky D, Dickson N, Hancox R, Harrington H, Caspi A. A gradient of childhood self-control predicts health, wealth, and public safety. Proceedings of the National Academy of Sciences. 2011;108(7):2693-2698. doi:10.1073/pnas.1010076108.

19. Barkley R. Emotional dysregulation is a core component of ADHD. In R. Barkley Ed. Attention-deficit hyperactivity disorder: A handbook for diagnosis \& treatment 4th Ed. New York: Guilford Press. 2015;81115 .

20. Graziano P, Garcia A. Attention-deficit/hyperactivity disorder and children's emotion regulation: a meta-analysis. Clinical Psychology Review. 2016;46:106-123. DOI:10.1016/j.cpr.2016.04.011.

21. Barkley R. Executive functioning and self-regulation viewed as an extended phenotype: Implications of the theory for ADHD and its treatment. In R Barkley Ed. Attention-Deficit Hyperactivity Disorder: a handbook for diagnosis and treatment, 4th Ed. New York: Guilford Press. 2015;405-434.

22. Nigg J. Attention and impulsivity. In D Cicchetti Ed. Developmental psychopathology: Risk, disorder and adaptation. 3rd Ed. New York: Wiley. 2016;3:591-646. 
23. Hinshaw S, Ellison K. ADHD: What everyone needs to know. New York: Oxford University Press. 2016

24. Willcutt E, Nigg J, Pennington B, Solanto M, Rohde L, Tannock R, Lahey B, et al. Validity of DSM-IV attention deficit/hyperactivity disorder symptoms, dimensions and subtypes. Journal of Abnormal Psychology. 2012;121:991-1010. doi:10.1037/a0027347.

25. Snyder J. Coercive family processes in the development of externalizing behavior: incorporating neurobiology into intervention research. In T Beauchaine, $\mathrm{S}$ Hinshaw Eds. The Oxford handbook of spectrum disorders. New York: Oxford University Press. 2016;282-302.

26. Pelham W, Fabiano G. Evidence based psychosocial treatments for attention deficit/hyperactivity disorder. Journal of Clinical Child and Adolescent Psychology. 2008;37:184-214. Doi:10.108015374410701818681.

27. Harvey E, Breaux R, Lugo-Candelas C. Early development of comorbidity between symptoms of Attention-Deficit/Hyperactivity Disorder (ADHD) and Oppositional Defiant Disorder (ODD). Journal of Abnormal Psychology. 2016;125:1554-167. doi:10.1037/ abn0000090.

28. Dishion T.\& Patterson G. The development and ecology of antisocial behavior: linking etiology, prevention, and treatment. In D. Cicchetti Ed. Developmental psychopathology 3rd Ed. New York: Wiley. 2016;3:647-678. DOI: 10.1002/9781119125556.devpsy315

29. Burke, J., Rowe, R., Boylan, K, Duku, E., Waldman, I., Stepp, S., \& Hipwell, A. Identifying the irritability dimension of ODD: Application of a modified bifactor model across five large community samples of children. Journal of Abnormal Psychology, 2014;123, 841-851.

30. Scott, S., A. Tharpar, D. Pine, J. Leckman, \& Snowling, M. (Eds.). Oppositional and conduct disorders. In Rutter's child and adolescent psychiatry (6th ed., pp. 913-930). New York: Wiley 2015 DOI: $10.1002 / 9781118381953 . c h 65$.

31. Lahey, B., \& Waldman, W. Annual research review: Phenotypic and causal structure of conduct disorder in the broader context of prevalent forms of psychopathology. Journal of Child Psychology and Psychiatry, 2012. 53(5), 536-557. doi: 10.1111/j.1469-7610.2011.02509.

32. Kimonis, E. Mash, Frick, P., McMahon, R. Barkley (Eds.),. Conduct and oppositional defiant disorders. In Child psychopathology (3rd ed., pp. 145-179). New York: Guilford Press 2014.

33. Loeber R., Burke, J., \& Pardini, D. Perspectives on oppositional defiant disorder, conduct disorder, and psychopathic features. Journal of Child Psychology and Psychiatry, 2009 509(1-2), 133-142 doi: 10.1111/j.1469-7610.2008.02011.x

34. Burke, J., Waldman, I., \& Lahey, B.. Predictive validity of childhood oppositional defiant disorder and conduct disorder: Implications for the DSM-V. Journal of Abnormal Psychology, 2010, 119(4): 739-751. doi: $10.1037 / \mathrm{a} 0019708$.

35. Murray, J., \& Farrington, D. Risk factors for conduct disorder and delinquency: Key findings from longitudinal studies. Canadian Journal of Psychiatry, 2010. 55(10): 633-642.

36. Center for Addiction and Substance Abuse at Columbia College. Addiction medicine: closing the gap between science and medicine. New York: Columbia University 2012.

37.Abram, K. New evidence for the role of mental disorders in the development of substance abuse. Journal of the American Academy of Child and Adolescent Psychiatry 2016. 55(4), 265-266.

38. Van Emmerick-van Oortmerssen, K., Glind, G., van den Brink, W., Smit, F., Crunele, C., Swets, M., \& Schoevers, R. Prevalence of attention-deficit hyperactivity disorder in substance use disorder patients: a metaanalysis and meta-regression analysis. Drug and Alcohol Dependence 2012, 122(1-2), 11-19. doi: 10.1016/j.drugalcdep.2011.12.007

39. Chassin, L., Colder, C., Hussong, A., \& Sher, K. D. Cicchetti (Ed.). Substance use and substance use disorders in Developmental psychopathology: Risk, disorder and adaptation (3rd ed., vol. 3., pp. 833-950). New York: Wiley 2016.

40. Molina, B., \& Pelham, W. Attention deficit/hyperactivity disorder and risk of substance use disorder: Developmental considerations, potential pathways, and opportunities for research. Annual Review of Clinical Psychology, 2014.10, 607-639. doi: 10.1146/annurevclinpsy-032813-153722.

41. Sibley, M., Pelham, W., Molina, B., Coxe, S., Kipp, H., Lahey, B., ... Ross, J. The role of early childhood ADHD and subsequent CD in the initiation and escalation of adolescent cigarette, alcohol, and marijuana use. Journal of Abnormal Psychology, 2014.123(2),362-374.

42. McQuade, J., \& Hoza, B, R. Barkley (Ed.). Peer relationships in children with ADHD in Attention-deficit hyperactivity disorder: A handbook for diagnosis \& treatment (4th ed., pp. 210-222). New York: Guilford Press 2015

43. DuPaul, G., \& Langberg, J, R. Barkley (Ed.),. Educational impairments in children with ADHD. In Attention-deficit hyperactivity disorder: A handbook for \& treatment (4th ed., pp. 169-190). New York: Guilford 2015.

44. Pardini, D. Empirically based strategies for preventing juvenile delinquency. Child and Adolescent Psychiatric Clinics of North America, 2016. 25(2): 257-268. doi: 10.1016/j.chc.2015.11.009.

45. Piquero, A, Brame, R., \& Moffitt, T. Extending the study of criminality and change: gender differences in the linkage between adolescent and adult offending. Journal of Quantitative Criminology, 2005. 21(2), 219-243. 